\title{
Why is a boycott of the elections a bad idea?
}

\author{
Madjid Eshaghi Gordji ${ }^{1}$, Gholamreza Askari ${ }^{2}$ and Hamed $\mathrm{Abdi}^{3}$
}

\begin{abstract}
By studying game theory, we find that the Nash equilibrium does not exist in some games or, if there is in one, does not describe a real event. Here we show that the matching pennies game with pure strategy has the solution, but this solution is a game that happens simultaneously with this game. Using this solution, we will answer the Brookings Institution's question of boycotting the elections whether the opposition's boycott of elections is, in different circumstances, a defeated strategy. A strategy that its result in most cases is a failure or political suicide and the least possible consequence by the opposition. The findings of this article show that in general, it can be concluded that the election boycott strategy is a dominated strategy, and most of the opposition groups that have used it have failed and they donated the playground to the ruling group.
\end{abstract}

Keywords: game theory, matching pennies game, opposition parties, election boycott.

\section{1- Introduction}

The concept of the public sphere is one of the key concepts in modern political thought as a situation in which actors are far from imposing and enforcing public affairs. In the book The Structural Transformation of the Public Sphere, Habermas expresses some attributes such as equality, freedom of expression, separation from the sphere of state authority and rationality, leading to public good for the concept of a general sphere (Habermas, 1991). Since the formation and expression of public opinion in a society requires public corporation, the modern conception of the public sphere has a direct relation to democracy and the electoral process as an expression of the representation of public opinion. However, attitudes are different from the concept of democracy and the context of political competition. On the one hand, we have the theory of liberal democracy, which emphasizes the value of institutions and structures. In other words, in this approach, politics is a policy to discipline processes in a manner that is coherent under an institution or structure (e.g. government, parliament, city councils, etc.). On the other hand, in the theory of communitybased democracy, the emphasis is on the formation of the collective identity of social groups based on a fundamental agreement or an agreement based on strategic thought. In the theory of deliberative democracy, special attention is paid to the role of the people and their free participation in political and social discussions and decisions. In this theory, the concepts of the rationality of human factors, as well as the concepts of dialogue and communicative action, also the counseling and consultation process, which are based on "the power of better reasoning to shape public opinion,"

${ }^{1}$ Corresponding author: Madjid Eshaghi, Department of Mathematics, Semnan University P.O. Box 35195-363, Semnan, Iran. E-mail: meshaghi@semnan.ac.ir

2 Department of Mathematics, Semnan University P.O. Box 35195-363, Semnan, Iran.

E-mail: g.askari@semnan.ac.ir

${ }_{3}^{3}$ Insnstitute for Cognitive and Brain Sciences (ICBS), Shahid Beheshti University, Tehran, Iran. E-mail:

h_abdi@sbu.ac.ir 
have a pivotal role. On the other hand, it is important to note that the advisory mechanism in deliberative democracy theory focuses on the behavior of the agents, or focuses on the context and structure of the environment.

Contrary to the views expressed which somehow see the public sphere as constructive interaction and public cooperation, some of the political theories are defined on the aggressive general sphere (the boundary between the friend and the enemy or the government and the opposition). The concept of the general realm of militancy and the public atmosphere of controversy in which conflict and struggle between different theories and desires never lead to a comprehensive outcome and a kind of overall satisfaction is one of the key concepts in the theory of radical democracy. The most important feature of this territory, contrary to what we see in other democratic theories, is the permanent existence of dissent, opposition and dissidents, as the determining part of the public sphere.

Influenced by the definition of German jurist and political theorist Carl Schmitt, the central category of politics, theorists of radical democracy theory consider the concept of conflict and opposition to be the focal point of politics. From this viewpoint, theorists such as Chantal Mouffe wrote; Antagonists and oppositions are in front of each other and try to define their definition against the opponent, and they do their interpretation hegemonic and dominant. Such an aggressive struggle between the competitors and the opposition leads to conflicts and aggressive opposition, which in my view is a vigorous condition of democracy (Mouffe, 2005).

Consequently, the concept of aggressive pluralism and debatable pluralism against the public sphere of Habermasian type (based on rationality and communicative action) are proposed to point out the importance of power relations in the public sphere and the constructive and necessary aspect of disagreement, conflict and opposition in the public sphere.

That is to say, Mouffe emphasizes that the purpose and function of the public sphere is not to shape and to provide a rational consensus and a general agreement but it is the transformation of opposition and antagonism into a controversy of agonism.

In this regard, attention is needed on an important point. Although radical democracy theorists accept Schmidt's doctrine that conflict and aggressiveness are the most fundamental of politics, they subject it to another fundamental condition, namely that this debatable environment should strengthen the principles and objectives of democracy. Thus, the fundamental function of the aggressive public sphere in radical democracy theory is that to transform the antagonism and opposition into debate, struggle, and the theoretical controversy of agonism by observing democratic principles.

While antagonism or opposition occurs between the two enemies who have no space symbolic common, agonism or struggle arises between two opponents, which have a common ground with each other, but each intends to impose his/her understanding in a hegemonic manner over another (Mouffe, 2000). Mouffe emphasizes that although two Competitors or opponents like two enemies are opposed to gaining stature over another, but unlike the enemy who wants another complete destruction, two opponents try to establish a hegemonic relationship (based on power and authority) on the other, and more importantly, they always keep respect to rightfulness of others. Mouffe calls this relationship a friendly enemy. Now, according to the introduction to the constructive foundations of the public sphere, we will return to our fundamental question. Is the boycott of elections by opposition, in different circumstances, a defeated strategy? We will continue to use the game theory to answer this question.

By studying game theory, we find that many games are related to each other and leave mutual effect on each other. A game may be the generator of the game before it, simultaneously and after itself. This article investigates the game produced the same time with the producer game. Moreover, this article argues that the complete dependent between producer game and produced game arises which occurs simultaneously. We show that the matching pennies game with 
pure strategy has the solution, but this solution is a game that happens simultaneously with this game. As a true example of the relationship between games, we show this dependency in the game between the government and opposition parties. With the help of this method, we answer the Brookings Institution's question of boycotting elections, why boycotting elections is a bad strategy.

\section{2- Game theory in political science}

The use of game theory in political science has focused on a common approach to areas of economic science and on topics such as fair distribution, political economy, public choice, war negotiating, and public choice theory (Ordeshook 1986, Brams 1994, McCarty and Meirowitz 2007). In each of these areas, researchers have proposed models of game theory in which models, players often show in the form of voters and political agents (politicians and intellectuals), governments, political interest groups and decision-makers. In the prototype models based on the game theory in political science, Anthony Downs's researches can be found in The "An Economic Theory of Democracy” book, which presents the corporate model of hotelling in the context of political trends. In the Downs model, political candidates are aware of the ideologies of a single-dimensional political atmosphere. In the other words, ideological information is available to political candidates and actors.

In general, the classical interpretation of game theory from the political field has been shaped to the terms of democratic peace. In this situation, due to the holding of public and free debate, information about the goals and intentions of the political actors is completely, clear and reliable sent to other agents (including political groups and voters). In contrast, in undemocratic societies where there is no free flow of information, it is almost impossible to know the extent to which the parties are committed to the commitment, as well as the intentions and goals of political leaders and agents. Therefore, if at least one of the political agents involved in a political conflict (such as parties) has adopted a nondemocratic approach (failing to send information for decision-making), distrust and unwillingness to compromise among political agents and people will happen (Levy and Razin, 2003).

In static game theory, players may be dissatisfied with the outcomes of the game, but because, in game situations, each player's choice of action is the best response to another player's action, they prefer not to change their choices. There are also games that do not have an equilibrium point. These issues discuss a fundamental question in a static state. How to get an optimal solution or strategy in static mode?

In 1928, matching pennies game was first introduced by Von Neumann (Von Neumann and Morgenstern 2007). This game is a zero-sum game which has no equilibrium with pure strategy but it has a unique equilibrium with mixed strategy. This equilibrium predicts that every player is winner of game with probability of 50\% (Eliaz and Rubinstein 2011). In the static game theory, players may be unsatisfied with payoff of game in equilibrium point but they prefer not to change their choice because selection of action of each player is the best response to action of another player. Also, there are games which have no Nash equilibrium (Osborne and Rubinstein 1994, Robinson and Goforth 2005). These problems bring up a main question in static game theory. How can one achieve a method for solving problems of static games?

In game theory to find solution in the static state from the pure strategy Nash equilibrium and the mixed strategy Nash equilibrium is used (Nash 1950, Brams 1994, Aumann and Brandenburger 1995, Blondel 1997, Belot, Crawford et al. 2013). The view that the solution should be chosen from the set of actions maybe is not always true and solution may be out of the game. Since, we seek to find a method of solving outside of the original game.

If a game produces other games, it is called a game-maker game. In general, if the games $G_{1} . G_{2} \ldots . G_{n}$ generate games $G_{1}^{\prime} . G_{2}^{\prime} \ldots . G_{m}^{\prime}$ then $G_{i}$ and $G_{i}^{\prime}$ are called producer and produced, respectively. For example, marriage, is an institution 
in which interpersonal relationships, establishes rights and obligations between them to lead a family. So, marriage is considered a cultural universal that requires games like matchmaking that happen. Therefore, marriage as producer game and matchmaking as produced game are called. In international relations, political relations between countries can create economic relation, so we consider political relations and economic relations as producer game and produced game, respectively. Hence, produced game help us to move towards find Nash equilibrium as a method for solving producer game, although there is the solution in produced game. We assume that recognition of the interval time of the produced game for players is based on the general information.

In the following conditions, it can be used from a game as a method for solving other game (main game):

- Main game has no Nash equilibrium;

- In the Nash equilibrium of main game, one of the players obtain payoff less than the other players' payoffs and is unsatisfied.

For a game whose players obtain the same payoffs in Nash equilibrium, we can't be used from a game as a method for solving other game, unless, players should be deciding together which bring in a game as a solution for other game. In the produced game, the players may change choice of action among the set of actions or change their set of actions. Players can design different games and change the situation to their benefit. The produced game can be designed based on decision of one or two players. Here we seek to find a method for solving matching pennies game in static state with pure strategy. Also, with help of game-maker games, we answer question of the Brookings Institute about why election boycotts are a bad idea.

Government and Opposition. In every political system, opponents are the integral part of that system. Political power relations and its mechanisms and combination of holders of this power are not accepted by all people and elites and this is the source of political opposition. In today's political literature, the word "opposition" is used but objection alone cannot be the basis for opposition. Formal or informal organization is the prerequisite of an opposition.

Political opposition thus varies markedly in strength and in character, not just between but among authoritarian and liberal regimes. In authoritarian polities, the government can be brutal or mildly repressive and, in the latter case, allow some groups and even parties to express a degree of (limited) dissent, only to clamp down if this opposition goes beyond what are regarded as 'acceptable' bounds (Blondel 1997).

Complexity of relation between state and opposition and different possibilities for their relations are more or less common among them in all political systems. The relation which is affected by social macrostructures, discourse factors and cultural factors, type of political systems and their institutional structures and is included in core of the political life of every society. In political and governmental system of the world, two oppositions are taken into account: legal or parliamentary and illegal. In the governments that have parliamentary system, opposition group is the group which is established in the parliament in opposition to function of government. In such systems, the opposition group has been recognized formally in the Constitutional law. In some governmental systems, opposition has no place in the Constitutional law and it is not regarded as one of the legal and formal institution.

In the less developed countries, opposition is referred to as the opposing parties who intend to overthrow the government of a society or weaken powerful authorities of the system and sometimes, they are evidently or secretly supported or covered by the dominant global authorities politically and financially.

Game of opposition parties and the government is matching pennies game. We assume government as row player and opposition party as column player. In many political systems have the property that government benefits from a "match", whereas opposition party benefits from a "mismatch". If the government and opposition have one opinion (agrees or disagrees), the government will gain payoff 1 and opposition will gain payoff -1. If the government's opinion 
disagrees with the opposition view, the government will gain payoff -1 and opposition will gain payoff 1 . Table of game $G_{1}$ is as follows.

Table 1. Game $G_{1}$ between Government and Opposition party

\begin{tabular}{lll}
\hline & \multicolumn{2}{c}{ Opposition } \\
\cline { 2 - 3 } Government & A & D \\
\hline A & $1,-1$ & $-1,1$ \\
\hline D & $-1,1$ & $1,-1$ \\
\hline
\end{tabular}

NOTE: $\mathrm{A}=$ agrees; $\mathrm{D}=$ disagrees

In this game, there are four pairs of actions and any pairs of actions is not Nash equilibrium but all four strategy index pairs are reasonable. In other words, strategies of a player in a game are the best responses to other players' strategies. Game $G_{1}$ is a game-maker game. We study the produced game $G_{2}$ simultaneous with $G_{1}$ that players are government and opposition party. In game $G_{2}$, players have two actions cooperation and non-cooperation. If both players cooperate with each other, they obtain payoff 2 . If a player cooperates and another one selects non-cooperation, the cooperating player will gain payoff 1 and the player who doesn't cooperate will gain payoff -1 . If both players select noncooperation, they obtain payoff -1 . Table of game $G_{2}$ is as follows:

Table 2. Game $G_{2}$ between Government and Opposition party

\begin{tabular}{lll}
\hline \hline & Opposition & \\
\cline { 2 - 3 } Government & $\mathrm{C}$ & $\mathrm{NC}$ \\
\hline $\mathrm{C}$ & 2,2 & $1,-1$ \\
\hline $\mathrm{NC}$ & $-1,1$ & $-1,-1$ \\
\hline
\end{tabular}

NOTE: $\mathrm{C}=$ cooperate; $\mathrm{NC}=$ non-cooperate.

The best strategy is cooperation and compromise. In other words, it means the settlement of the issues through negotiation. Therefore, the Nash equilibrium is $(C, C)$. The Nash equilibrium of the produced game, we steer to provide a solution that to players for go out of this difficult situation of matching pennies game will help. Hence, we use a game as a method for solving other game which include the optimal strategy for both players. Therefore, we show that game of matching pennies with pure strategy has solution but this solution is a Nash equilibrium in other game which occurs simultaneously with this game.

For example, one can refer to election boycott when considering game between government and opposition part. Could opposition forces achieve their goals through election boycott? Using the strategic games, we seek to answer this question. It can be found that producer game of matching pennies $G_{1}$ occurs in the initial conditions and the produced game $G_{2}$ is occurring concurrently. In the producer game, players have two actions to agree (A) or disagree (D) with 
the elections. In the produced game, opposition actions are participation (C) in election or non-participation (NC) in election (election boycott) and actions of the government are elections (C) or no elections (NC). With help this method, it can be concluded that elections strategy dominates over the non-elections strategy for the government. As a result, the government holds elections in such conditions. On the other hand, participation in election strategy dominates over the election boycott strategy for the opposition parties. Therefore, it can be concluded that the opposition party will lose and will obtain worse result if it continues games based on the dominated election boycott strategy of the static state.

In the produced game $G_{2}$, the choice of election boycott strategy by the opposition ends with the result $(1,-1)$, when the government intends to hold elections. A research report in Brookings Institute has studied efficiency of election boycott strategy in 171 various countries (Frankel 2010). Results of Brookings Institute also show that there is no case in any country which the opposing forces against the dominant government reach their goals by adopting this method of rejection of election in order to delegitimize election and always loser of this games are the group which has boycotted the election.

In Iraq, the Sunni community decided to boycott the elections in January 2005 in protest of the Sunnis.

This decision is one of the great strategic blunders in the post-Saddam era, and in those sensitive situations earning only five of 275 parliamentary seats. From produced game $G_{2}$, it can be concluded that the Sunni community's decision not to participation (NC) in elections is a dominated strategy and achieve the result (C, NC). In the December 2005 elections, the Sunni community decided to participation (C) elections. This decision increased the seats of the parliament from 5 to 55 (Frankel 2010). Therefore, participation in elections is a strategy dominates over the election boycott strategy for the opposition parties. This strategy leads to a pair of action $(\mathrm{C}, \mathrm{C})$ for both players, which simultaneously is an equilibrium for games $G_{2}$ and $G_{1}$.

The Islamic Action Front (IAF) is Jordan's main Islamist political party. The IAF in Jordan decided to boycott the parliamentary elections in the years 1997, 2010 and 2013. In 2003, the IAF earned 16 seats that demonstrating the benefits of participation. In 2016, after two periods of boycotting the election, IAF with the coalition with Christians and prominent national figures and formed the National Coalition for Reform (NCR) which won 15 seats, including 10 seats won by the IAF (Singh 2017). Therefore, the benefits of participating in elections are more than the boycott of elections. In other words, the boycott of elections is a bad strategy that leads to the political suicide of the opposition parties.

A constitutional referendum was held throughout Turkey on 16 April 2017 on whether to approve 18 proposed amendments to the Turkish constitution that were brought forward by the governing Justice and Development Party (AKP) and the Nationalist Movement Party (MHP). These reforms included the establishment of a presidential system in place of the current parliamentary system, the abolition of the post of prime minister, the increase of parliament seats from 550 to 600, and amendments to the High Council of Judges and prosecutors (Grigoriadis 2018). Ruling party AKP and opposition MHP are the signatories of the amendments The Republican People's Party (CHP) and the People's Democratic Party (HDP) were opposed to these reforms. Amendments proposed by opposition parties and non-governmental organizations faced heavy criticism. The referendum was held under a state of emergency that was declared following a failed military coup attempt in July 2016. Early results indicated a 51-49\% lead for the "Yes" vote (Strachota 2017).

Published statistics indicate that out of a total of $8 / 5$ million eligible voters who did not participate in the Turkish referendum, much of them are affiliated with the Kurdish opposition to the Turkish government, mostly in the Kurdish regions of southern and southeastern Turkey. The opposition groups did not participate in the referendum from a radical 
stance and their lack of presence has strengthened the power of the ruling party of justice and development. While, if only 4 million people did not boycott the referendum and the lead for "No" vote, Erdoğan's plan to change the constitution failed.

Those who leave the polls or will be indifferent to them will regret. Historical memory does not record regret of opposition groups, but it only records the victory of the ruling party and the changes that it creates, which future generations will pay for it.

In general, we would like to know the answer of following questions, because almost will be complete our method .

Question A: How can one achieve a general model from game-maker games that lead to find solution in static game theory?

According to our method in this paper to find solution of matching pennies game, we ask the following question.

Question B: Can be used in each conditions from the produced games as solution of producer games?

\section{3- Cognitive approach}

As shown, the Nash equilibrium point lies in the matching pennies game as a game producer, in a cooperation game that runs concurrently with the matching pennies game. In this game, Nash equilibrium is in a position where both agents, in terms of rational decision-maker, choose the strategy of cooperation. In other words, whenever both main players in the election, namely the government and the opposition, cooperate with each other, they will get the most benefit.

Now, if we concentrate our attention on the game of cooperation (as the determinant of the status of the profits of the agents), and try to analyze each agent from the cognitive and behavioral point of view (as agents with bounded rationality), will face with a fundamental question. The question is how does the initial trust shape in choosing a cooperative strategy, form the players of the cooperative game? In other words, how can we get more rates that are cooperative?

In general, in a social situation, in which the number of participants in the event (here in the election) is very high, the prediction of the collective behavior of activists will be very difficult and complex. However, if the level of transparency and access to information in the community were such that believing can be formed in accordance with the goals and desires of each of the actors of the game, then it would be hoped that the prediction of the behavior of the activists would be successful. The importance of the ability to predict behavior in persuade activists in co-operate behavior is shown in the Greenberg and Lalev simulation. The results of Greenberg and Lalev simulation show that higher levels of ability to predict behavior lead to higher rates of collaboration between actors (Grinberg \& Lalev, 2008).

The structure of the recurring neural network used for this simulation is a recursive elemental neural network and use for estimating the different levels of the predictive ability of the cast in five predictive levels. At the first level, the actor is aware of the status of the game, and on the fifth level, the actor uses the prediction of 10 fictitious games to decide for cooperation or non-cooperation.

Accordingly, can endorse the importance transparency of information in the electoral space as an effective factor in shaping the believing network in line with the goals and desires of each of the actors, which ultimately leads to the choice of cooperation strategy.

From the perspective of cognitive functions and according to the cognitive limitations of each agent (limited rationality) in choosing a cooperative strategy in order to maximize the benefits, the role of the ability to predict collective behavior 
by actors in events such as elections is very important. Accordingly, in order to achieve the best possible prediction of the final state of the election competition (cooperation or non-cooperation), the transparency of the information in the electoral space needs to be such that it leads to the formation of a believing network, which is coincident with the reality and the facts.

\section{4- Conclusion}

In the political competition field between the governing government and the opposition forces and in order to anticipate an optimal strategy, in addition to the structural status of the game that is shown through matching pennies, attention is drawn to the following:

1. Identification of agents that are effective in the final result (government, nation, opposition, media, influential people ...) and the level of the impressment of each actor in final result (political weight of the agents)

2. The priority and the interests of each of these agents (the strategic plan of the agents)

3. Interacts rate, disagrees, or conflicts with others (the political context of the competition)

Items 1 and 2 relate directly to the information transparency of the electoral space and the availability of individuals and political activists to information. As it mentioned in the cognitive approach, the selection of the most effective possible strategy by each actor depends on their ability to predict the status of each of the actors (including the process of detecting actors, receiving the priorities and strategic interests of each actor and ...) is effective in the electoral process.

On the other hand, attention to the political context of competition (item 3 ) has a particular importance. To explain the political context of competition, which can cover a wide range of levels of Interact (from controversy to conflict), reference to political ideas can be a solution. In political literature, the concepts of antagonism and agonism are used to explain the status of the political context of the competition. If the area of competition is a place of hostility among the actors, the concept of antagonism will indicate the situation, and if this conflict is stretched and the controversy among the actors is approached, the concept of the agonism will be explained of context of competition.

In the matching pennies game, identifying the main actors of the competition is very important. But in the game of cooperation and non-cooperation, whatever determines the status of the outcome matrix, in addition to the priorities and interests of each of the actors (which is quantitatively equivalent), is a competitive context that leads to cooperation or non-cooperation. We believe that in a context where agonism (disagreement) is dominant, the probability of achieving collaboration is more than the one in which antagonism (hostile) dominates.

Results of this research are in line with the research reports of the Brookings Institute about election boycott strategy. In the game between the government and opposition, the dominant strategy for the government is election and the dominant strategy for the opposition parties is no election boycott considering the environmental conditions and time interval and preferences of the players in the producer game and produced game. Election boycott policy has failed almost in all cases and the boycotters didn't favor it. Winner of this game is the dominant party which has begun to change the Constitutional Law in their favor when the majority has become stronger in the Legislative and didn't worry about reduction of participation or legitimacy of the government.

\section{Competing interests}

The authors declare that they have no competing interests. 


\section{References.}

Aumann, R. and A. Brandenburger (1995). "Epistemic conditions for Nash equilibrium." Econometrica: Journal of the Econometric Society: 1161-1180.

Belot, M., et al. (2013). "Players of Matching Pennies automatically imitate opponents' gestures against strong incentives." Proceedings of the National Academy of Sciences 110(8): 2763-2768.

Blondel, J. (1997). "Political opposition in the contemporary world." Government and Opposition 32(4): $462-486$.

Brams, S. J. (1994). Theory of moves, Cambridge University Press.

Eliaz, K. and A. Rubinstein (2011). "Edgar Allan Poe's riddle: Framing effects in repeated matching pennies games." Games and Economic Behavior 71(1): 88-99.

Frankel, M. (2010). Threaten but participate: why election boycotts are a bad idea, Foreign Policy at Brookings.

Grigoriadis, I. N. (2018). The Rising Tide of Populist Majoritarianism in Turkey. Democratic Transition and the Rise of Populist Majoritarianism, Springer: 53-72.

Grinberg, M. and E. Lalev (2008). The Role of Anticipation on Cooperation and Coordination in Simulated Prisoner's 335 Dilemma Game Playing. Workshop on Anticipatory Behavior in Adaptive Learning Systems, Springer.

McCarty, N. and A. Meirowitz (2007). Political game theory: an introduction, Cambridge University Press.

Nash, J. F. (1950). "Equilibrium points in n-person games." Proceedings of the National Academy of Sciences 36(1): 48-49.

Ordeshook, P. C. (1986). Game theory and political theory: An introduction, Cambridge University Press.

Osborne, M. J. and A. Rubinstein (1994). A course in game theory, MIT press.

Robinson, D. and D. Goforth (2005). The topology of the 2x2 games: a new periodic table, Psychology Press.

Singh, M. (2017). "Parliamentary Election in Jordan, 2016." Contemporary Review of the Middle East 4(3): 297-318.

Strachota, K. (2017). "The constitutional referendum-another step towards a New Turkey."

Von Neumann, J. and O. Morgenstern (2007). Theory of games and economic behavior (commemorative edition), Princeton university press. 